\title{
Forecasting on China's final consumption in 2021
}

\author{
X.L. Liu ${ }^{1,2,3, a *}$, Y.X. Dou ${ }^{1,3}$, K.X. Zhai ${ }^{3}$, S.H. Huan ${ }^{1,3}$ \\ ${ }^{1}$ Academy of Mathematics and Systems Science, Chinese Academy of Sciences, Beijing, China \\ ${ }^{2}$ Center for Forecasting Science, Chinese Academy of Sciences, Beijing, China \\ ${ }^{3}$ University of Chinese Academy of Sciences, Beijing, China
}

\begin{abstract}
In the vital stage of China's economic development pattern turning to the "double-cycle" dominated by sizable domestic cycle, the analysis and prediction of final consumption is of great significance to achieve stable economic growth with quality and efficiency, and improve people's quality of life. Based on the analysis of the change trend of the final consumption and its structure and the main influencing factors, this paper forecasts the final consumption of China in 2021 by the method of summing sub- items. It is expected that China's final consumption will be with a nominal growth rate in the range of 9.6-10.6\% yearon-year in 2021.
\end{abstract}

\section{Introduction}

In 2020, facing novel coronavirus pneumonia epidemic and the complex and severe domestic and international environment, the final consumption expenditure in China accounted for $54.3 \%$ of GDP, which was 11.2 percentage points higher than the total capital formation, slightly lower than $55.4 \%$ in 2019 , but still at a historically high level compared with 2018 (Fig. 1). In 2020, final consumption continued to play a ballast role in the stable operation of the economy. With the continuous improvement of the domestic epidemic prevention and control, the recovery of the national economy, the gradual improvement of the business situation of enterprises, and the continuous liberalization of offline consumption scenarios, the boosting effects of policies issued by central and local governments, the domestic consumer market recovers gradually. In October and November 2020, during the National Day, Mid-autumn holiday, and the Double 11 period, China's consumer market ushered in a small upsurge of growth. The monthly value of the total retail sales of consumer goods increased by $1.2 \%$ and $3.7 \%$ year-on-year. In the vital stage of China's economic development pattern turning to the "double-cycle" dominated by sizeable domestic cycle, it is of great significance to analyze and predict the changing trend of final consumption for realizing the stable development of China's economy, social stability, and harmony, and building a modern socialist country in an all-round way.

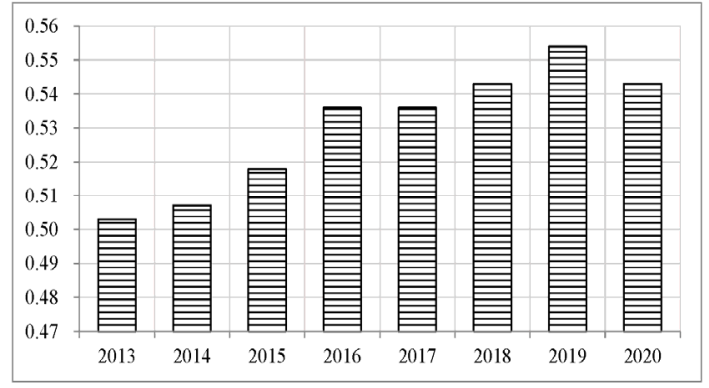

Fig 1. The proportion of the final consumption expenditure accounted for in China's GDP

The analysis and prediction of final consumption are of great significance to actively play the leading role of new consumption, achieve stable economic growth with quality and efficiency, and improve people's quality of life. Scholars have explored the influence of different factors on the final consumption [1]; used the Organisation for Economic Cooperation and Development data to confirm that population is an important factor affecting consumption $[2,3]$; used micro-survey data to analyse expenditure of different age groups in the United States and Serbia [4]; researched consumption behaviour during retirement in the UK $[5,6]$; and used China's microhousehold survey data to conduct empirical researches about the relationship between demographic transition and household consumption in China. But China's microhousehold survey data often lacks the consumption of rural households. Secondly, based on US household data, Yun, Mark, and Yuan believed that household borrowing and household indebtedness affected current consumption [7]. Fan and Yavas researched the crowding-out effect of mortgage payments on household consumption with China household data [8]. Browning, Gørtz, and Leth-

\footnotetext{
a* Corresponding author: e-mail xiuli.liu@amss.ac.cn
} 
Petersen, and Burrows also explored the impact of household housing debt on household consumption in Denmark and the UK from housing prices $[9,10]$. Finally, because mobile payment is just emerging and there is less annual data of online payments available, there is little related literature about the relationship between online payment and household consumption considered by Zheng and Liu [11]. However, the latest data showed that the popularity of rural e-commerce had promoted rural households' consumption. Rural online retail sales increased from 180 billion yuan in 2014 to 1800 billion yuan in 2020. Ji, Ying, and Liu studied residents' consumption from the perspective of tax policy and put forward suggestions on reducing taxes and fees, strengthening income redistribution, and guiding consumption to return [12]. Fu and wang studied the negative impact of COVID-19 on China's economy and consumption [13]. Hong and Liu analyzed residents' consumption based on the positive relationship between disposable income and consumption. They suggested policies such as increasing residents' income and reducing housing prices to release residents' consumption potential [14]. Yang and $\mathrm{Gu}$ found that the development of new retail has a certain effect on improving the quantity and quality of residents' consumption [15]. This paper analyzed the changing trend of the total final consumption, its structure, and its main impacting factors, forecasted China's final consumption in 2021 by the method of summing sub-items that considered new emerging impacting factors like rural e-commerce.

\section{The Change Trend of Final Consumption in China}

From January to October 2020, China's consumer expectation index, satisfaction index, and confidence index showed a fluctuating upward trend at a historically high level. By October 2020, the expectation index, satisfaction index, and confidence index were 125.2, 116.6, and 121.7, respectively, which showed that households had strong consumption intention (Fig. 2).

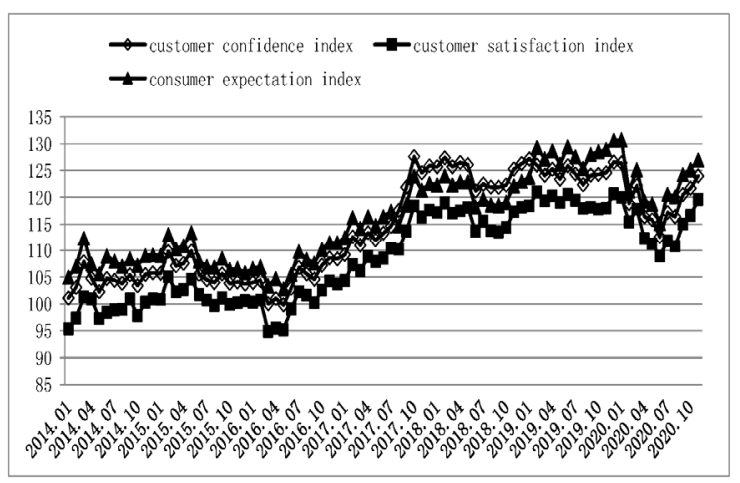

Fig 2. China's consumer expectation index, satisfaction index, and confidence index

From the final consumption structure perspective, the proportion of household consumption in the final consumption fluctuated between $70.0 \%$ and $74.7 \%$ from 2001 to 2019 . The proportion of household consumption expenditure dropped to $70.0 \%$ in 2019 , the lowest since 2000. From the perspective of urban and rural structure, the proportion of rural household consumption in household consumption decreased year by year from 2001 to 2018. Accordingly, the proportion of urban household consumption increased year by year, from $67.9 \%$ in 2001 to $78.6 \%$ in 2018 . While this trend changed slightly in 2019, The proportion of urban households' consumption decreased slightly by 0.3 percentage point from 2018 (Table I).

Table1. Changes of China's Final Consumption Structure from 2001 to 2019.

\begin{tabular}{ccccc}
\hline Year & $\begin{array}{l}\text { The proportion of } \\
\text { household consumption }\end{array}$ & $\begin{array}{l}\text { The proportion of } \\
\text { government consumption }\end{array}$ & $\begin{array}{l}\text { Proportion of rural } \\
\text { households' consumption } \\
\text { in households' } \\
\text { consumption }\end{array}$ & $\begin{array}{l}\text { Proportion of urban } \\
\text { households' consumption } \\
\text { in households' } \\
\text { consumption }\end{array}$ \\
\hline $\mathbf{2 0 0 1}$ & & & $32.1 \%$ & $67.9 \%$ \\
$\mathbf{2 0 0 2}$ & $74.0 \%$ & $26.0 \%$ & $30.9 \%$ & $69.1 \%$ \\
$\mathbf{2 0 0 3}$ & $74.4 \%$ & $25.6 \%$ & $30.0 \%$ & $70.0 \%$ \\
$\mathbf{2 0 0 4}$ & $74.6 \%$ & $25.4 \%$ & $28.9 \%$ & $71.1 \%$ \\
$\mathbf{2 0 0 5}$ & $74.7 \%$ & $25.3 \%$ & $27.8 \%$ & $72.2 \%$ \\
$\mathbf{2 0 0 6}$ & $74.2 \%$ & $25.8 \%$ & $26.9 \%$ & $73.1 \%$ \\
$\mathbf{2 0 0 7}$ & $73.3 \%$ & $26.7 \%$ & $25.6 \%$ & $74.4 \%$ \\
$\mathbf{2 0 0 8}$ & $73.3 \%$ & $26.7 \%$ & $25.0 \%$ & $75.0 \%$ \\
$\mathbf{2 0 0 9}$ & $73.2 \%$ & $26.8 \%$ & $24.2 \%$ & $75.8 \%$ \\
$\mathbf{2 0 1 0}$ & $73.3 \%$ & $26.7 \%$ & $23.0 \%$ & $77.0 \%$ \\
$\mathbf{2 0 1 1}$ & $73.4 \%$ & $26.6 \%$ & $23.3 \%$ & $76.7 \%$ \\
$\mathbf{2 0 1 2}$ & $73.2 \%$ & $26.8 \%$ & $22.8 \%$ & $77.2 \%$ \\
$\mathbf{2 0 1 3}$ & $73.2 \%$ & $26.8 \%$ & $22.5 \%$ & $77.5 \%$ \\
$\mathbf{2 0 1 4}$ & $73.2 \%$ & $26.8 \%$ & $22.4 \%$ & $77.6 \%$ \\
$\mathbf{2 0 1 5}$ & $73.9 \%$ & $26.1 \%$ & $22.2 \%$ & $77.8 \%$ \\
$\mathbf{2 0 1 6}$ & $73.4 \%$ & $26.6 \%$ & $21.9 \%$ & $78.1 \%$ \\
$\mathbf{2 0 1 7}$ & $73.4 \%$ & $26.6 \%$ & $21.5 \%$ & $78.5 \%$ \\
$\mathbf{2 0 1 8}$ & $72.9 \%$ & $27.1 \%$ & $21.4 \%$ & $78.6 \%$ \\
$\mathbf{2 0 1 9}$ & $72.5 \%$ & $27.5 \%$ & $21.7 \%$ & $78.3 \%$ \\
\hline
\end{tabular}

From the perspective of household consumption structure, from 2013 to 2020, the consumption proportion of urban households in the food category decreased by 1.0 percentage point, the proportion of consumption in transport and communications increased before 2016 with peak $13.8 \%$ then decreased, in 2020 the ratio was $12.9 \%$. 
The proportion of consumption in health care and medical services increased 1.9 percentage point; the consumption proportion of rural households in the food category decreased by 1.5 percentage point, the proportion of consumption in transport and communications increased by 1.7 percentage point and the proportion of consumption in health care and medical services increased by 1.4 percentage point from 2013 to 2020 . The consumption of other items had a slight fluctuation but showed a stability trend in all (Fig. 3). This shows that China's households' consumption extends from material life to the spiritual and cultural level, with obvious upgrading characteristics.

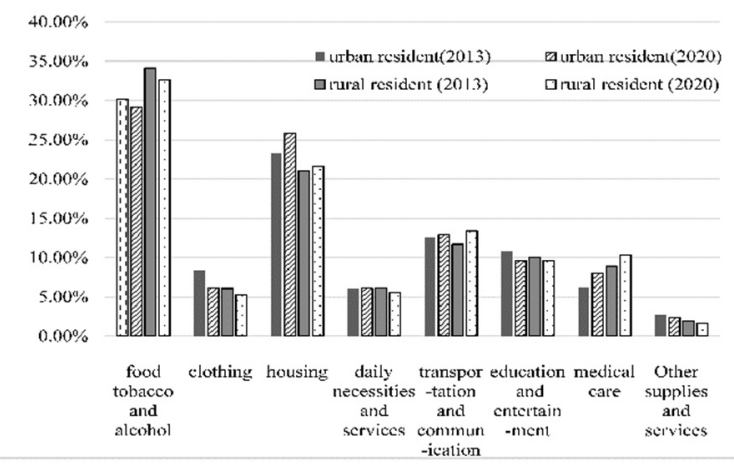

Fig 3. The composition of per capita consumption expenditure of urban and rural residents in China in 2013 and 2020

Data source: National Bureau of Statistics

From the perspective of government consumption, China continued to implement an active fiscal policy in 2020. The tax and fee reduction are important embodiments of this policy. Affected by COVID-19 and other factors, the national revenue had declined more, and the fiscal revenue and expenditure conflicts were intensified. Financial departments firmly implemented the requirements of more active fiscal policies to maintain a sustained and stable economic recovery. Fiscal revenues and expenditures were improved quarter by quarter. In 2020, China's general public budget and expenditure reached 245588.8 billion yuan, increasing $2.8 \%$ year on year.

Income is the most direct and dominating factor in determining consumption. According to the National Bureau of Statistics, the average annual growth rate of urban households' disposable income stayed at $9.2 \%$ from 2010 to 2019. In the same period, rural households' disposable income increased by $11.7 \%$ in nominal terms. Rising per capita disposable income increased households' consuming willingness. In 2020, China's urban households' per capita disposable income was RMB 43834, with nominal growth of $3.5 \%$ and a real increase of $1.2 \%$ after deducting the price factor. The per capita disposable income of rural households was RMB 17131, with nominal growth of $6.9 \%$. After deducting the price factor, the actual growth was $3.8 \%$, faster than that of urban households (Fig. 4) . In 2020, the urban-rural income ratio decreased to 2.56 from 2.64 in the same period of 2019 .

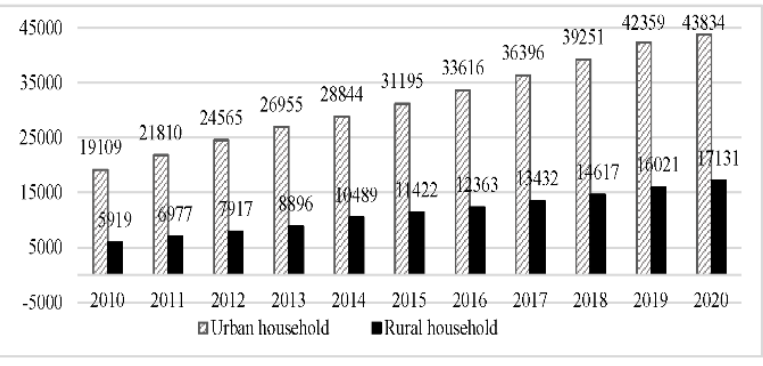

Fig 4. Per capita disposable income of urban and rural households (yuan/person)

Data Source: National Bureau of statistics of China

From the perspective of consumption favourable factors, the COVID-19 promoted the digital economy's development and released potential consumption demand. China's online retail market continues to grow, driving the momentum of consumption. The Post-1990s have become the backbone of household consumption, and the Post2000s have gradually become the main force of online consumption. Overseas consumption mostly returned during the outbreak of COVID-19. The pace of upgrading commodity consumption is speeding up. There is a strong demand for intelligent energy-saving goods, green environmental protection products, healthcare products, fresh food and other commodities, and the service consumption of catering, tourism, culture and entertainment continues to recover and revitalize. Policies of strengthening agriculture, benefiting farmers, and enriching farmers had been strengthened, and a series of favourable conditions have continuously released the potential of the rural consumption market. The continuous promotion of tax abatement and fee reduction will increase enterprise investment and personal consumption and promote the regular circulation of the economy.

Family debt has become a main factor affecting the consumption of Chinese residents in the new era. According to the National Bureau of Statistics, the amount of household sector loans rose from RMB 2549.6 billion in 2011 to RMB 7851.4 billion in 2018 , which increased 22 times in 18 years. The proportion of loans in disposable income increased from $5.7 \%$ to $14.6 \%$ (Fig. 5). Among them, housing loans are the main cause of high household debt. By the end of 2020, the balance of personal housing loans reached RMB 34.4 trillion, 3.5 times the balance of personal housing loans (RMB 980 million) in 2013.

The generation of the 1990s has become the backbone of Chinese consumption, while the generation of the 2000 s has gradually become the main force of online consumption. From 2020 to 2021, there will be about 190 million people born in the 1990 s and 150 million in the 2000 s. With the development of society, young people are more willing to consume and have less awareness of saving. Affected by the upgrading of consumption level and the two-child policy, the scale of the maternal and infant market continues to expand. The size of China's maternal and infant market reached 3.6 trillion yuan in 2019 and would grow steadily in the near future. Female consumer market was estimated to reach 10 trillion yuan in 2020, and the "lipstick economy" and "medical beauty economy" were getting more and more points [16]. At the 
same time, as sales channels continue to sink, the consumption potential of consumers from third-tier cities, fourth-tier cities and urban markets has gradually emerged. The COVID-19 has prompted gradual repatriation of foreign consumption. In 2020, the duty-free sales of China's outlying islands would be about 30 billion yuan, more than double of that in 2019 [17]. China's future dutyfree economy and other fields will be expected to achieve further development and growth [18].

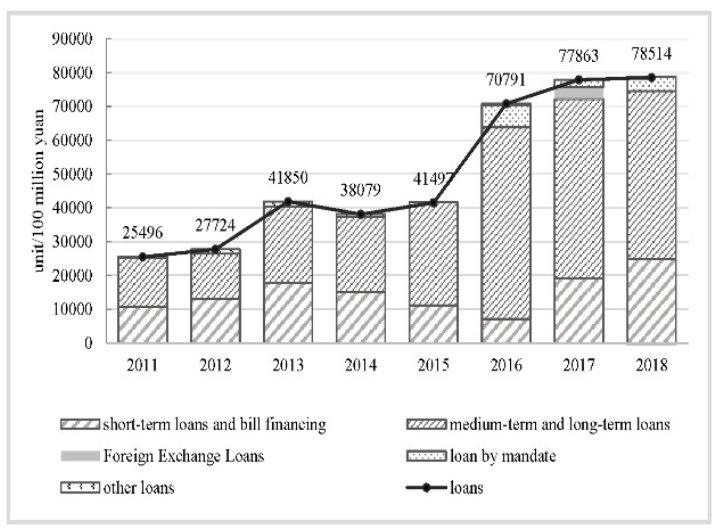

Fig 5. China's household sector loan structure from 2011 to 2018

Data Source: National Bureau of statistics of China

Other factors restricting consumption growth include: the lag of supply side transformation which is difficult to meet the demand of consumption upgrading, inadequate policy support system, and imperfect management mechanism and so on.

\section{Results and Suggestions}

Based on the analysis of the change trend of the total final consumption, its structure, and the main influencing factors, this paper forecasts the final consumption of China in 2021 by the method of summing sub-items. It is expected that China's final consumption will show a bounce trend in 2021, but the growth rate will be slower than that in 2019, with a nominal growth rate of 9.6-10.6\% year-on-year.

Here are some suggestions based on this study.

(1) Taking various measures to comprehensively improve the training of digital talents and promote the rapid and healthy development of the digital economy.

We should accelerate the construction of new engineering disciplines for the digital economy and actively develop new majors in the digital field. Promote the integration of computer science, data analysis or other filed and expand the scale of training digital talents.

(2) Actively foster mid-to-high-end service consumption.

We should accelerate the development of elderly care and rehabilitation services, and foster a series of the brand elderly care institutions. Promote smart medical services, introduce quality medical resources, and build platforms for diagnosis. It is suggested to encourage the development of medical cosmetology consumption featuring the personalized customization.
(3) It is suggested to assign consumption tax to local governments gradually and encourage local governments to continue to pay attention to people's livelihood and consumption.

The current consumption tax belongs to the central government, which restricts the enthusiasm of local governments. If the consumption tax is gradually allocated to local governments, and making it an important source of tax revenue for local governments, it will be conducive to continuously expanding the growth potential of local tax revenue.

\section{Acknowledgements}

This work was supported by National Nature Science Foundation of China under Grant No. 71874184.

\section{References}

1. Varlamova J, Larionova N. "Macroeconomic and demographic determinants of household expenditures in OECD countries," Procedia Economics \& Finance, vol.24, pp.72-733, 2015.

2. Foster A C. "Consumer expenditures vary by age," Beyond the Numbers, vol.4, pp.1-11, 2015.

3. Biljana R, Petar V. "Household age structure and consumption in Serbia," Economic Annals, vol.57, pp.79-101, 2012.

4. Gomez R, Foot D K. "Age structure, income distribution and economic growth," Canadian Public Policy, vol.29, pp.141-162, 2005.

5. Mao R, Xu J W. "Demographic transition, consumption structure disparities and industrial growth," Population Research, vol.38, pp.89-103, 2014. (In Chinese)

6. Ni H F, Li S T, He J W. "Impacts of demographic changes on consumption structure and savings rate," Population \& Development (In Chinese), vol.20, pp.25-34, 2014.

7. Yun K K, Mark S, Yuan M. "Aggregate consumption and debt accumulation: An empirical examination of US household behaviour," Cambridge Journal of Economics, vol.39, pp.93-112, 2015.

8. Fan Y, Yavas A. "How Does Mortgage Debt Affect Household Consumption? Micro Evidence from China," Real Estate Economics, 2018.

9. Browning M, Gørtz M, "Leth-Petersen S. Housing wealth and consumption: A micro panel study," Economic Journal, vol.123 pp.401-428, 2013.

10. Burrows, Vivien. "The impact of house prices on consumption in the UK: A new perspective," Economica, vol.85 pp.92-123, 2018.

11. Zheng S, Liu X L. "Prediction of China's household consumption and its structure in new period," Journal of Systems Science and Mathematical Sciences, vol.38, pp.1149-1159, 2018. (In Chinese)

12. Ji J B, Ying T, Liu J M. "On the tax policies of boosting domestic consumption and promoting the 
dual-cycle pattern," Taxation Research, vol.11, pp.510, 2020. (In Chinese)

13. Fu Z H, Wang Z G. "Impact of COVID-19 on residents' consumption and countermeasures," Fiscal Science, vol.4, pp.33-40,2020. (In Chinese)

14. Hong Y, Liu Z Y. "Research on the relationship between consumption and household disposable income," Modern Business, vol.1, pp.27-29,2020. (In Chinese)

15. Yang $\mathrm{X}, \mathrm{Gu} \mathrm{M} \mathrm{Y}$. "New retail development, consumer consumption and logistics model optimization," Journal of Commercial Economics, vol.5, pp.26-30, 2021. (In Chinese)

16. CBN Business Data Center Survey. 2020 Women's Quality Life Trend Insight Report 2020. https://www.cbndata.com/report/2222/detail [202004-07]

17. Sina Finance."Internal Loop" Drives Growth of Overseas Consumption Return.

https://baijiahao.baidu.com/s?id=1675454746267730 $300 \& w f r=$ spider\&for $=p c$ [2020-08-19]

18. Fu Y F. 2020 consumer market in-depth review: there are changes, challenges and opportunities. https://www.sohu.com/a/438978875_100171523 [2020-12-18] 